FINAL REPORT

U.S. Department of Energy

\title{
The Migration and Entrapment of DNAPLs in Physically and Chemically Heterogeneous Porous Media
}

\author{
Co-Principal Investigators: \\ Linda M. Abriola and Avery H. Demond \\ Department of Civil and Environmental Engineering \\ The University of Michigan \\ Ann Arbor, MI 48109-2125
}

Project Number: 54680

Grant Number: DE-FG07-96ER14702

Project Duration: 9/15/1996 to 9/15/2000 


\section{TABLE OF CONTENTS}

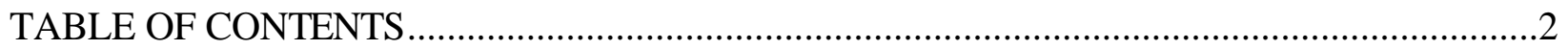

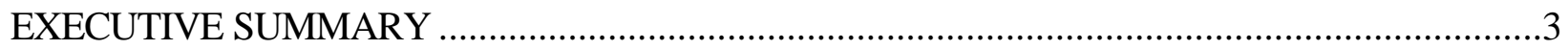

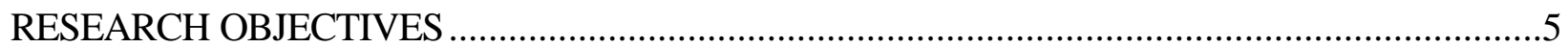

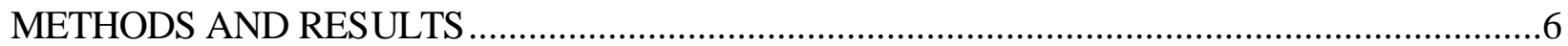

RELEVANCE, IMPACT AND TECHNOLOGY TRANSFER …….........................................

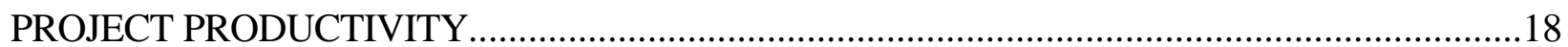

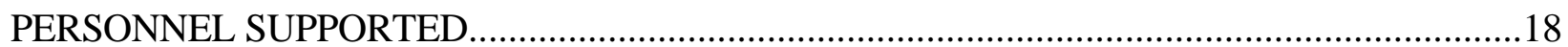

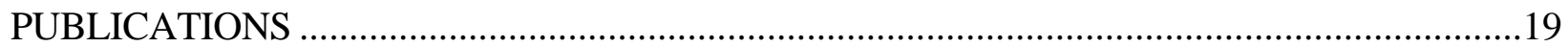

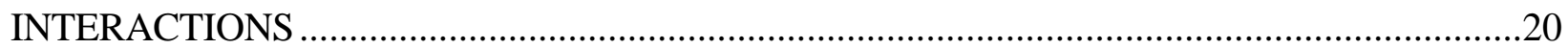

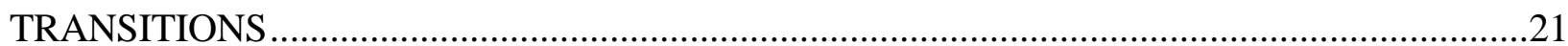

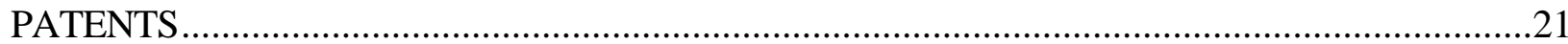

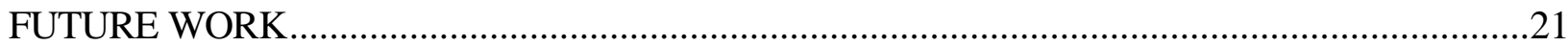

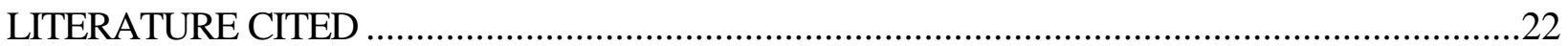




\section{EXECUTIVE SUMMARY}

Dense nonaqueous phase liquids (DNAPLs) pose a significant threat to soil and groundwater at Department of Energy (DOE) sites. Evidence suggests that subsurface chemical heterogeneity is present at many of these sites as a result of spatial and temporal variations in aqueous phase chemistry, contaminant aging, mineralogy and organic matter. The presence of such heterogeneity may significantly influence DNAPL migration and entrapment in the saturated zone. Despite its potential importance, the physics of DNAPL flow in chemically heterogeneous systems has not been adequately investigated, and multiphase flow simulators typically assume that subsurface soils are completely water-wet and chemically homogeneous. If this assumption does not hold, large errors may be introduced into estimates of DNAPL migration and remediation. This report highlights research, funded by the DOE Environmental Management Science Program (EMSP), aimed at improving our understanding of and ability to simulate the influence of subsurface chemical heterogeneity on DNAPL flow and entrapment. The concentrations of the surface-active solutes octanoic acid (OA) and dodecylamine (DDA) in aqueous solutions were shown to directly affect fundamental transport properties of the aqueous and organic phases, such as water-NAPL capillary pressure-saturation relationships. This behavior was the consequence of changes in interfacial tension and/or solid phase wettability. Solid phase mineralogy and surface coatings also altered capillary relations significantly through changes in solid phase wettability. DNAPL residual saturation was found to systematically vary from 5 to $25 \%$ for experimental soils composed of various mass fractions of untreated (water-wet) and organosilane treated (DNAPL-wet) Ottawa sands. Two-dimensional DNAPL infiltration experiments also demonstrated that subsurface chemical heterogeneity significantly influences DNAPL migration due to differences in entrapment behavior and capillary barrier effects at interfaces of capillary contrast (chemical or textural). 
Theoretical models to quantify and describe these experimental data have been developed and incorporated into a two-dimensional multiphase flow simulator. This simulator was used to predict the migration and entrapment of a DNAPL, tetrachloroethylene (PCE), in experimental systems and to conduct numerical experiments in coupled chemically and physically heterogeneous systems at larger scales and over a wider range of heterogeneity characteristics. Experimental and numerical studies indicate that the spatial distribution of subsurface chemical characteristics should be quantified to improve the prediction of DNAPL fate and persistence, and that this information may be of equal importance to hydraulic conductivity variations in some systems. A more complete understanding of the influence of chemical heterogeneity on DNAPL migration and entrapment may lead to improved methods for DNAPL recovery and containment during aquifer remediation operations. 


\section{RESEARCH OBJECTIVES}

The improper storage and disposal of hazardous dense nonaqueous phase liquids (DNAPLs) at DOE facilities have resulted in the widespread contamination of the subsurface environment [National Research Council, 1998]. Riley et al. [1992] report that approximately 80\% of DOE facilities have reported groundwater contaminated by chlorinated solvents (DNAPLs). Regulated exposure levels for many DNAPLs are several orders of magnitude below their vapor pressure and solubility limits. Consequently, subsurface DNAPL contamination is a problem of serious concern at DOE sites. Applying conventional remediation techniques to such waste sites has proven largely ineffective, since many DNAPLs are sparingly soluble in water and cannot be dislodged by pumping [MacDonald and Kavanaugh, 1994]. Realizing this shortcoming, there is a strong incentive for the Environmental Management Science Program (EMSP) to foster the development of more efficient cleanup technologies that will significantly reduce remediation costs, duration, and risks. Hampering the attainment of this goal is the difficulty in identifying and quantifying contaminant sources, predicting and monitoring contaminant fate, and implementing remediation activities at many DOE sites National Research Council, 1998].

Significant research has focused on the processes governing DNAPL migration and entrapment following their release to the subsurface environment [Kueper et al. 1993, Pennell et al. 1994, Dawson and Roberts 1997, Hofstee et al. 1998a, Hofstee et al. 1998b, Oostrom et al. 1999a, b]. A number of these studies have investigated the effects of subsurface heterogeneity on the fate of pure DNAPLs. However, few have specifically addressed the effects of variations in subsurface wettability. Natural materials have a variety of wetting characteristics. For example, coal, graphite and talc are intermediate- to organic-wet whereas more common aquifer materials such as quartz and carbonate are water-wetting [Anderson, 1987a]. In addition to natural wettability variations due to differing mineral surfaces, temporal wettability alterations are also important. Surface-active agents in a waste mixture may sorb to the mineral surfaces and significantly change the wettability [Powers and Tamblin, 1995, Powers et al. 1996]. It is apparent that variable subsurface wettability is possible in many situations and requires further study.

Many of the wastes reported at DOE sites are complex mixtures. For example, DNAPLs and surface-active compounds such as organic acids and bases were frequently disposed concurrently [Riley et al., 1992]. Subsurface chemical heterogeneity also occurs at many DOE sites as a result of spatial and temporal variations in aqueous, DNAPL, and solid surface chemistries. Large errors may therefore be introduced into numerical simulations of DNAPL migration and remediation when models are based upon assumptions of chemical homogeneity. As a result, the primary objective of this research is to improve our understanding of and ability to simulate the influence of subsurface chemical heterogeneity on DNAPL flow and entrapment in the saturated zone. Laboratory and numerical investigations have been conducted for a matrix of organic contaminants and porous media encompassing a range of wettability characteristics.

Specific project objectives include:

(i) the quantification of two-phase aqueous/DNAPL interfacial and hydraulic properties;

(ii) development and assessment of constitutive hydraulic property and continuum based multiphase flow models;

(iii) exploration of DNAPL migration and entrapment in heterogeneous systems at larger scales, and;

(iv) development of innovative remediation schemes. 


\section{METHODS AND RESULTS}

\section{(i) Quantification of aqueous/DNAPL interfacial and hydraulic properties.}

Methods

Several types of measurements were conducted to determine the effects of solution chemistry on the interfacial and subsurface transport properties of priority contaminants from DOE waste sites. These included the measurement of $\mathrm{pH}$, surface tension, contact angle, bottle tests, and capillary pressure-saturation relationships. Representative systems of five components, including a nonaqueous fluid, water, electrolyte, surface-active co-contaminant, and solid phase were selected. The LNAPL $\mathrm{o}$-xylene was chosen as a representative fuel hydrocarbon. Tetrachloroethylene (also known as perchloroethylene or PCE) was chosen as a typical DNAPL because of its widespread use and resulting contribution to numerous contamination sites.

A series of experiments was conducted to explore the influence of representative surface-active agents, dodecylamine (DDA) and octanoic acid (OA), on interfacial properties in PCE-water-quartz systems [Lord et al., 1997ab, 1999]. A Du Nouy ring tensiometer was used to measure the surface tension between the PCE and air as well as pure Milli-Q water and air. The surface tension of oxylene was obtained using the Axisymetric Drop Shape Analysis (ADSA) technique [Cheng et al., 1990]. In this method a drop of liquid is suspended from a fine gauge needle and photographed. The Laplace equation of capillarity is then used to calculate the surface tension from the digitized drop profile. The ADSA method was also used to obtain interfacial tension measurements. For that case, a drop of nonaqueous fluid was created in a bath of water. Before making the measurements, the liquids were pre-equilibrated with one another for at least a week. $\mathrm{pH}$ adjustments were made by adding small amounts of $\mathrm{HCl}$ or $\mathrm{NaOH}$ and surface-active agents DDA and $\mathrm{OA}$ were added before the equilibration period. Contact angle measurements were made by imaging a sessile drop of the nonwetting fluid on a smooth quartz plate immersed in a bath of the wetting fluid. The ADSA apparatus was used to perform the imaging and analysis of the images to determine the angle of intersection of the droplet with the quartz plate.

Additional experiments were designed to examine the influence of organic acids on the wetting properties of solid surfaces of varying mineralogy. Bottle tests were used to assess the wettability behavior of porous media composed of quartz, iron oxide coated quartz, aluminum oxide coated quartz, limestone $\left(\mathrm{CaCO}_{3}\right)$, and shale in the presence of a dyed mineral oil and various aqueous solutions $(\mathrm{pH}=6.5$ ) of $\mathrm{OA}$ (the anionic form of $\mathrm{OA}$ dominates at $\mathrm{pH}=6.5$ ).

The capillary pressure-saturation relationships measured in this study were primary drainage curves, obtained using the recently developed [Salehzadah and Demond, 1999] version of the traditional Tempe cell apparatus. This cell employs a smaller sample volume and precisely manufactured membranes as capillary barriers to obtain rapid, reliable results. Clean soils were equilibrated with water and the nonaqueous fluid for at least a week. Then the sample chamber was packed on a vibrating table and sealed while fully saturated with water. An organic liquid reservoir was connected to the top of the cell when measuring the water-nonaqueous liquid capillary pressuresaturation curve. Pressurized air was applied to incrementally force organic liquid into the cell. The pressure applied was measured using precise digital regulators and the volume of displaced fluid was determined by measuring the meniscus in a long capillary tube connected to the outlet of the cell. Alternatively, the air was directly connected to the cell to measure the capillary pressure-saturation curve for an air-liquid system. 
In addition to the modified Tempe cell apparatus, an automated system [Bradford and Leij, 1995] was used to measure capillary pressure-saturation relationships and residual saturations for PCEwater systems. Water- and NAPL-wet ceramic plates $(0.5$ bar $)$ were placed on the top and bottom of the initially water saturated soil column, respectively. Adjusting the boundary conditions of the fluid reservoirs and then opening the solenoid valves initiated an outflow period. PCE flowed to the column, displacing the water. The transient liquid pressures and outflows were monitored, using pressure transducers and a data logger, until the fluid saturations equilibrated with the imposed boundary conditions; i.e., flow ceased and hydrostatic pressures were attained. The final saturations and pressures represent an equilibrium point on the $P_{c}-S$ curve according to the pressure cell approach. Subsequently, a new set of boundary and initial conditions were specified for another outflow period and a new point on the $\mathrm{P}_{\mathrm{c}} \mathrm{S}$ curve. Residual saturations were obtained when changes in the boundary conditions of a particular phase no longer changed the phase saturation (the relative permeability was zero).

Results:

Results of experiments conducted to explore $\mathrm{pH}$ effects are illustrated in figures $1 \mathrm{a}$ and $1 \mathrm{~b}$, where the measured interfacial properties (interfacial tension and contact angle) are presented as a function of $\mathrm{pH}$ in the presence of OA or DDA. 


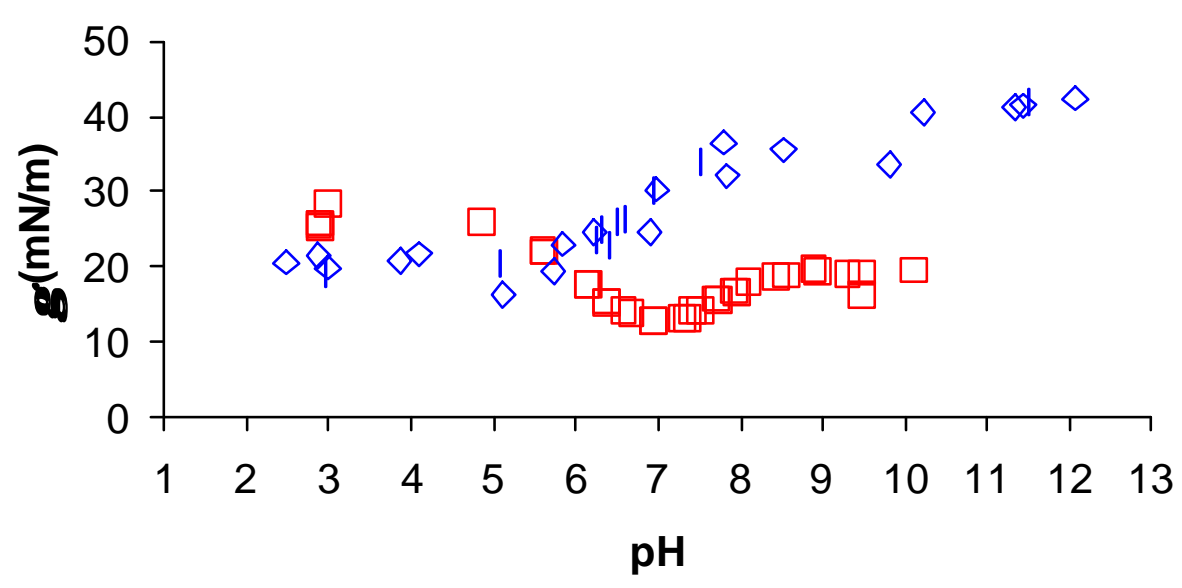

$\square$ Octanoic Acid I Dodecylamine

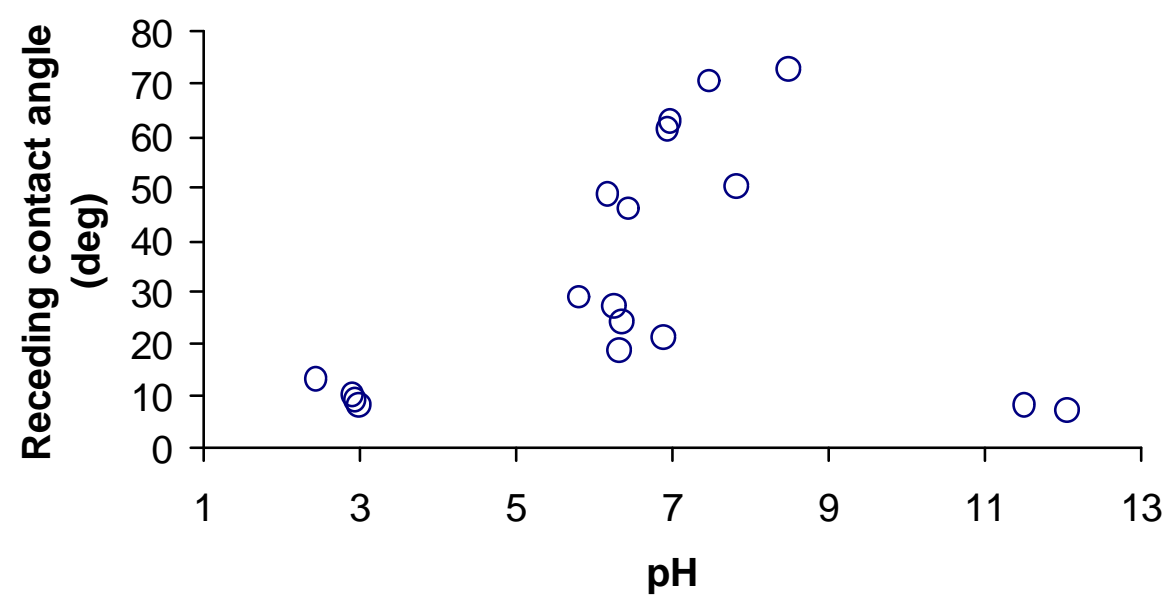

Figure 1 - (a) Interfacial tension for PCE-water-quartz systems containing octanoic acid and dodecylamine as a function of $\mathrm{pH}$ (top). (b) Receding contact angle for PCE-water-quartz systems containing octanoic acid and dodecylamine as a function of $\mathrm{pH}$ (bottom).

DDA and OA exhibit pH dependent acid-base speciation in aqueous solution, resulting in aqueous chemistry-dependent interfacial tension and/or wettability in these systems. When the neutral species of DDA ( $\mathrm{pH}>10.6)$ and $\mathrm{OA}(\mathrm{pH}<4.8)$ was dominant, minimal changes to interfacial properties were observed because of preferential partitioning of DDA and OA into the NAPL. In contrast, the cationic form of DDA $(\mathrm{pH}<10.6)$ sorbed both to the quartz and the NAPL-water interface, altering the wettability from water-wet to neutral wettability and lowering the NAPL-water interfacial tension. The anionic form of $\mathrm{OA}(\mathrm{pH}>4.8)$ sorbed only to the NAPL-water interface, lowering the interfacial tension by as much as $50 \%$.

The bottle tests determined the wetting characteristics of soils of different mineralogy. In the absence of OA, all of the soils except the shale were observed to be strongly water-wet; i.e., the shale was partially NAPL-wet. In contrast, in the presence of $0.1 \mathrm{M} \mathrm{OA}$, only the quartz soil was waterwet; the soils composed of iron oxide coated quartz, aluminum oxide coated quartz, limestone, and shale were strongly NAPL-wet. 
Experiments were conducted to explore the influence of solution chemistry of organic acids and bases on the capillary pressure relationship. The influence of OA and DDA concentration on the capillary pressure relationship for a tetrachloroethylene-water-quartz system was examined [Lord 1999] and compared to previous [Lord et al., 1997a,b] results obtained for the same solutes in an oxylene-water-quartz system. Despite the different properties of PCE and o-xylene, including polarity, aromaticity, density, and pure solvent interfacial tensions, the speciation, sorption and partitioning of the solutes were similar and influenced the capillary pressure relationship similarly. When the $\mathrm{pH}$ was above the $\mathrm{pKa}, \mathrm{OA}$ is preferentially in an anionic form and, therefore, OA remains in the aqueous phase, where it influences the interfacial tension to a greater extent. This behavior is reflected in the primary drainage capillary pressure relationship shown in Figure 2.

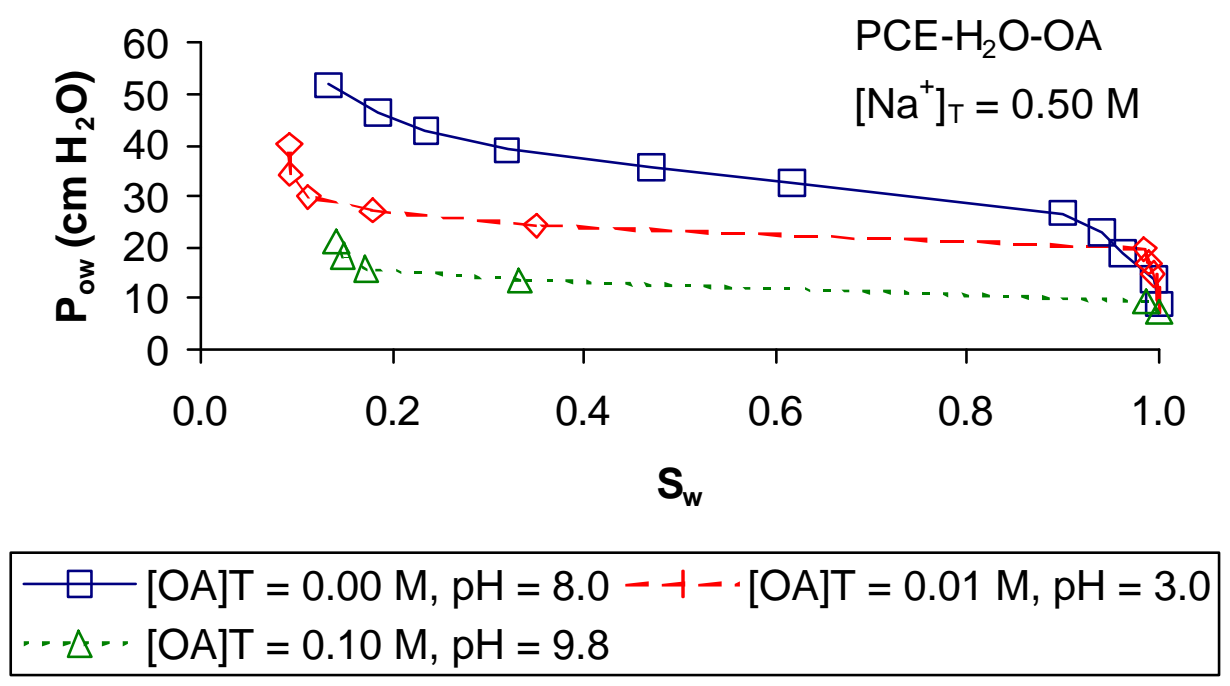

Figure 2- Primary drainage capillary pressure curves for PCE-water-Ottawa sand systems at various pHs and total octanoic acid concentrations.

Here the capillary pressure at a given aqueous phase saturation is observed to be lower at $\mathrm{pH}$ values above the pKa. A similar lack of dependence on the nature of the organic liquid phase was observed in the DDA-NAPL-water-quartz systems. In this case, however, capillary pressure relations were affected by $\mathrm{pH}$ dependent changes in both interfacial tension and solid wettability (cf. Figure 1).

Additional research efforts have focused on the determination and quantification of hydraulic property relations for synthetic fractional wettability porous medium (systems composed of known water- and organic-wet fractions), and for media having uniform, well-defined, solid surface chemistries (quartz, Fe oxide coated quartz, Al oxide coated quartz, limestone, and shale). Results indicate that the magnitude and shape of the capillary pressure curves are strongly dependent on the fractional wettability of the system. Figure 3 shows that as the DNAPL-wet fraction of a soil increases, for a given saturation and saturation history, the DNAPL-water capillary pressure decreases, becoming negative at higher water saturations. 


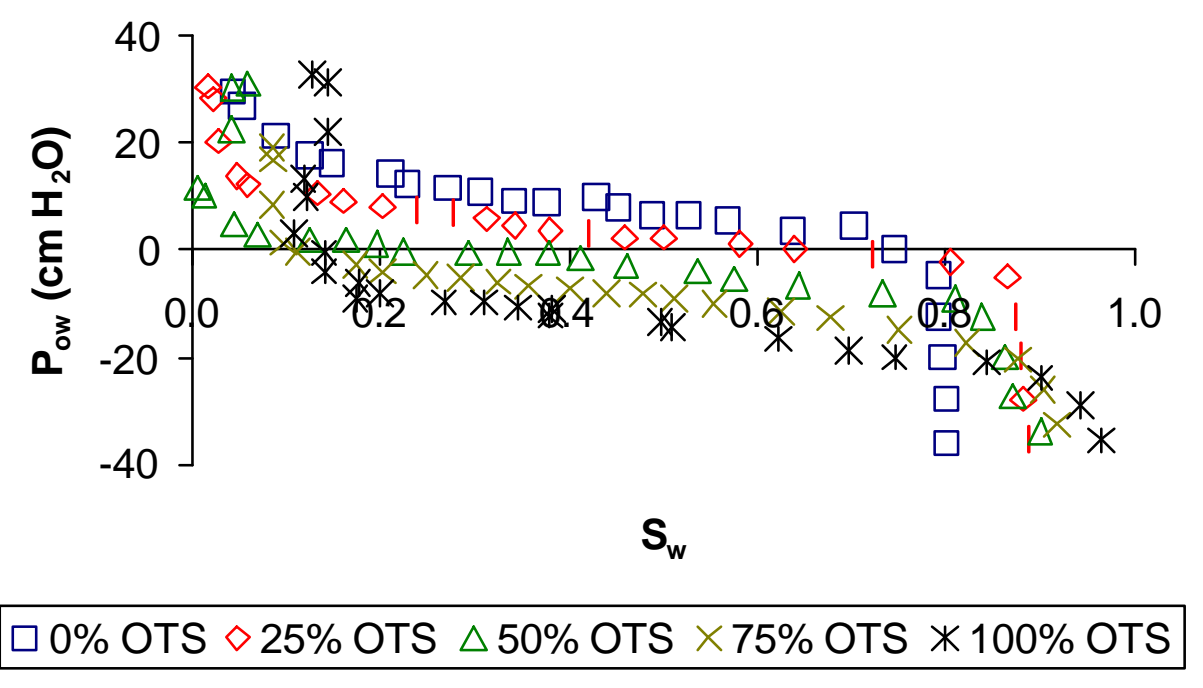

Figure 3 - PCE-water imbibition capillary pressure curves for various fractional wettability f35-f50 Ottawa sand systems. Percentages correspond to the organic-wet sand fraction.

After exposure to a $0.1 \mathrm{M}$ solution of $\mathrm{OA}(\mathrm{pH}=6.5)$ followed by prolonged rinses with Milli-Q water (approximately $50 \mathrm{PV}$ ), the hydraulic properties for some of these sands exhibited a much more pronounced variation in wettability depending upon the soil's solid surface characteristics (cf. Figure 4).

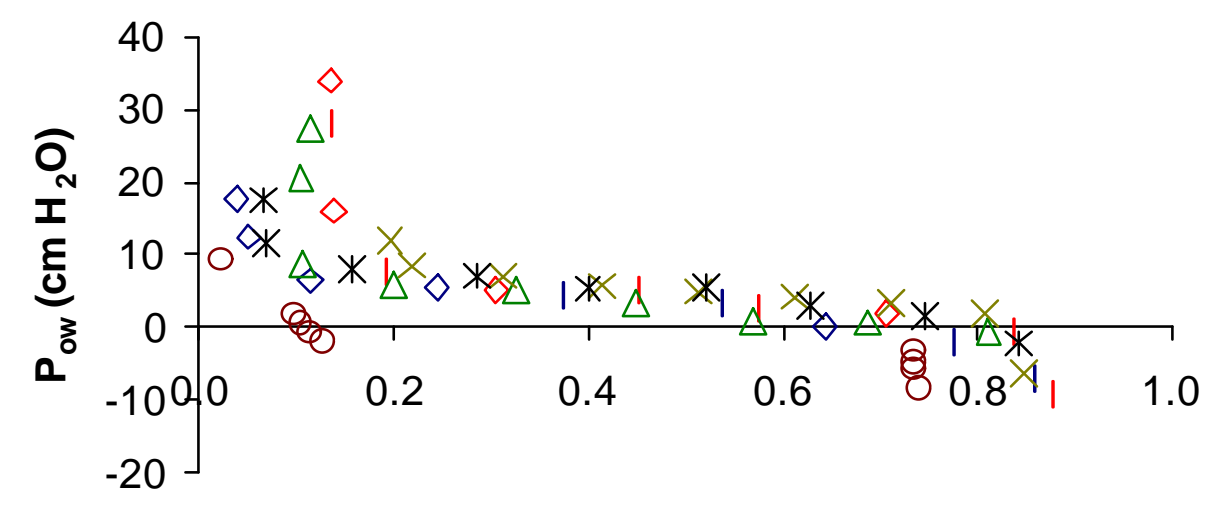

$\mathrm{S}_{\mathrm{w}}$

I Ottawa I Fe oxide $\triangle$ Al oxide $\times$ CaCO3 $*$ Wagner o Shale

Figure 4 - PCE-water imbibition capillary pressure curves for $\mathrm{f} 20$ - $\mathrm{f} 30$ sands and the indicated solid surface mineralogies after exposure to $0.1 \mathrm{M} \mathrm{OA}$ and 50 pore volumes of Milli-Q water.

Recall that wettability bottle test for these soils demonstrated that iron oxide coated quartz, aluminum oxide coated quartz, limestone, and shale were strongly NAPL-wet in the presence of $0.1 \mathrm{M} \mathrm{OA}$ and mineral oil. Additional measurements of hydraulic property relations for these soils in the presence of various OA concentrations are planned.

For the sands with well defined fractional wettability and solid surface chemistry, transient outflow measurements were undertaken with the automated setup that was used to determine capillary pressure relations. This transient information is currently being used to determine relative permeability relations according to history matching procedures. Due to the inability of previously developed 
multiphase models to handle the measured time dependent water and DNAPL pressure boundary conditions, a new one-dimensional multiphase flow simulator has been developed to solve the direct problem (simulation of outflow data). This simulator has been successfully coupled with a nonlinear least-squares fitting routine to solve the indirect problem (optimization of hydraulic property model parameters to the outflow data). Figure 5 shows a representative plot of the observed and simulated fit to the transient cumulative outflow data.
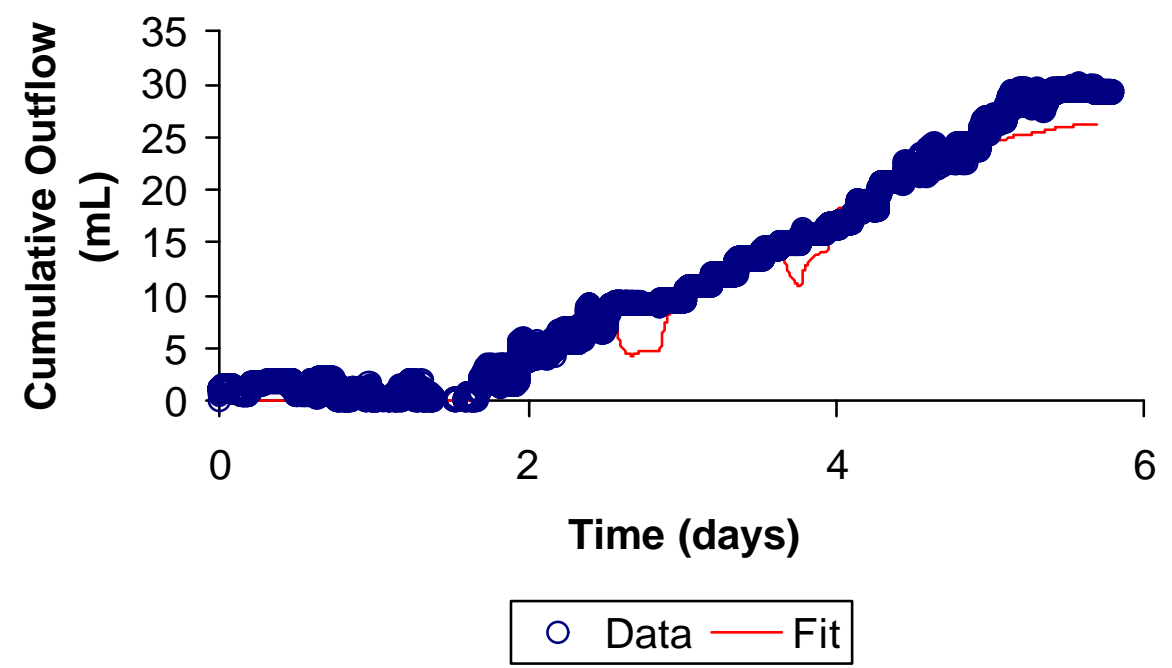

Figure 5 - Representative observed and simulated cumulative outflow behavior (water-wet f35-f50 Ottawa sand).

Residual water and DNAPL saturations were also found to systematically vary as a function of fractional wettability [Bradford et al., 1999]. The magnitude of residual DNAPL saturations varied by 5 to $25 \%$ for the experimental sands. Figure 6 presents the residual DNAPL saturation for various sand grain size distributions and wettability conditions. Note that the residual organic saturation in finer textured sands reached a minimum a intermediate wetting conditions, whereas residual saturations in coarser textured sands decreased asymptotically with increasing fraction of organic-wet sand. These observations were explained in terms of plausible interactions between NAPL films and ganglia, and surface area considerations Bradford and Abriola, 2001]. For media with NAPL-wet solids, an inverse correlation of residual organic saturation with grain size can be easily explained in terms of the relationship between increasing solid surface area and decreasing permeability [Carman, 1937]. 

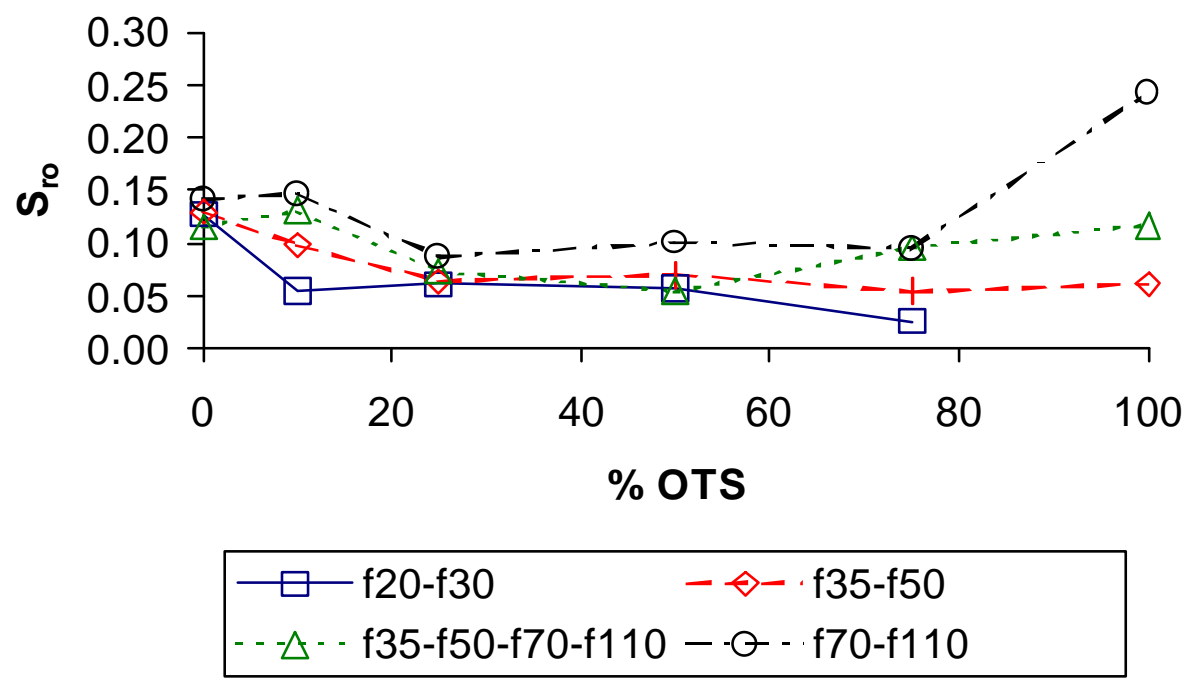

Figure 6 - Residual PCE saturation (Sro) as a function of organosilane treated soil mass fraction for the indicated sieve sizes of Ottawa sands.

(ii) Development and assessment of constitutive hydraulic property and continuum based multiphase flow models.

Methods:

The PI's have adapted the two-dimensional finite difference multiphase flow simulator $\mathrm{M}$ VALOR [Abriola et al., 1992] to explore the influence of coupled physical and chemical heterogeneity on DNAPL migration and entrapment in the saturated zone [Bradford et al., 1998ab]. Saturation independent and saturation dependent wettability effects on the hysteretic hydraulic property relations are presently included. The turning bands method [Thompson et al., 1989] is used to generate spatially correlated heterogeneous permeability distributions for model input. This method assumes a lognormal distribution of intrinsic permeability [Woodbury and Sudicky, 1991] with a specified mean and covariance structure. The spatial correlation structure of intrinsic permeability is described using an exponentially decaying covariance function [Sudicky, 1986].

Two methods for describing formation chemical heterogeneity are considered: specification of the contact angle or the organic-wet solid mass fraction. When the contact angle is less than $90^{\circ}$ water is considered the wetting fluid, conversely when the contact angle is greater than $90^{\circ}$ water is considered the non-wetting fluid. Spatial distributions of chemical heterogeneity are generated by correlation with intrinsic permeability. Capillary properties are obtained from the intrinsic permeability according to Leverett scaling. Wettability effects on the capillary pressure-saturation relations are modeled by contact angle scaling or curve "shifting" (fractional wettability systems). Wettability effects on relative permeability relations are modeled with a Burdine model, modified to weight contributions of wetting and non-wetting fluid pore classes [Bradford et al., 1995 and 1998].

\section{Results:}

One-dimensional simulations in physically homogeneous porous media demonstrated that as the contact angle or organic-wet fraction increases, the maximum organic liquid saturation increases and the depth of infiltration decreases. Wettability effects on the predicted organic saturation distribution were found to be more pronounced for increasing contact angles than for increasing organic-wet fractions (fractional wettability). This result is attributed to the dependence of the fractional wettability hydraulic 
properties on the historic minimum water saturation. Simulations also demonstrated that capillary barrier effects could occur at soil chemical property interfaces. The presence of such barriers can lead to dramatically higher organic liquid saturations.

Two-dimensional simulations for coupled physically and chemically heterogeneous aquifers revealed that the presence of chemical heterogeneity could dramatically influence the predicted distribution of organic saturation in aquifer formations. In physically homogeneous coarse textured systems, increasing the contact angle or organic-wet fraction of a soil produced a prolonged slow migration of the DNAPL, creating larger contaminated aquifer regions with lower organic saturations. In coupled physically and chemically heterogeneous systems, interfaces of capillary property contrast (soil texture or soil wettability) led to higher organic saturations, increased lateral spreading, and decreased depths of organic liquid infiltration (Figure 7).

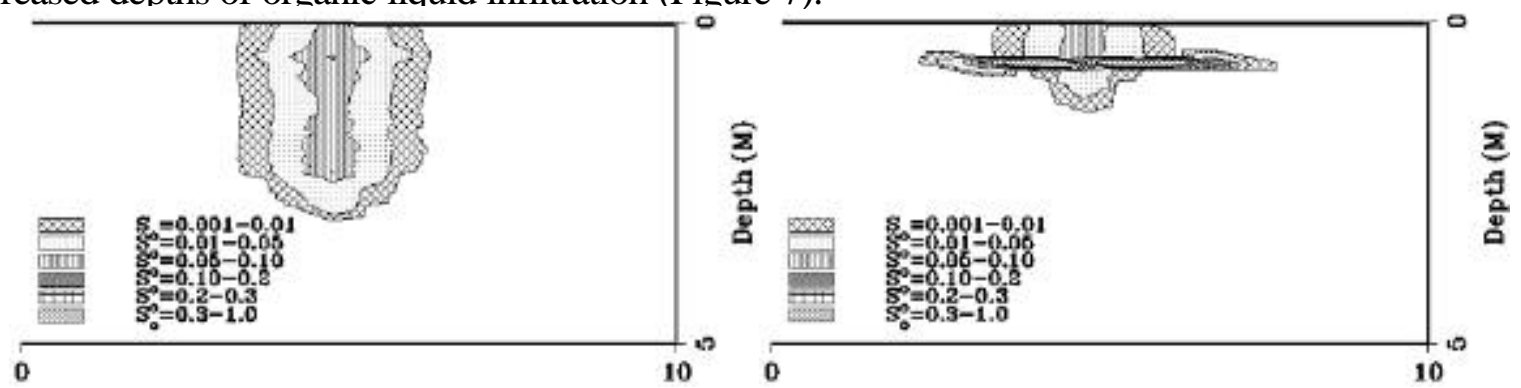

Figure 7 - Simulated spatial distribution of PCE saturation after 10 days when a physically heterogeneous aquifer (left and right) is completely water-wet (left) and when contact angle is inversely correlated with the intrinsic permeability and the geometric mean contact angle is $66^{\circ}$ (right).

(iii) Exploration of DNAPL migration and entrapment in heterogeneous systems at larger scales. Methods:

PCE infiltration experiments were conducted in a "two-dimensional" sandbox, $1.7 \mathrm{~cm}$ thick [O'Carroll et al., in preparation]. The box was constructed with an aluminum back and sidewalls as well as a tempered glass front, facilitating visual observation of PCE migration. The bottom of the tank was sealed with chemically inert PLV 2100 Base Material Fluoroelastomer viton coating (Pelseal Technologies, Newtown, PA, 18940). Wells at either end of the box were screened with stainless steel mesh $(0.015 \mathrm{~cm} \times 0.015 \mathrm{~cm})$. The volume in each well was approximately $10 \mathrm{~cm}^{3}\left(0.6 \mathrm{in}^{3}\right)$.

The system was wet packed in 1 to $2 \mathrm{~cm}$ intervals. Each layer was mixed gently, to ensure no layering, packed down with a wooden plunger and vibrated. The sandbox contained three sand layers at the bottom of the tank as shown in figure 8 .

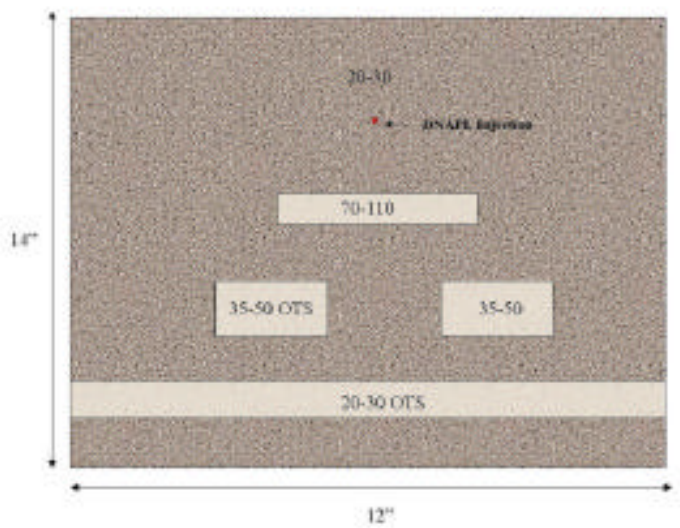


Figure 8 - Schematic of sand tank used for flow and entrapment experiments.

The lowest $0.6 \mathrm{~cm}$ fine water-wet layer $(\mathrm{F} 70 / \mathrm{F} 110)$ at the bottom of the tank was emplaced to ensure that PCE would not reach the aluminum surface at the bottom of the tank. Moving upwards, the sandbox contained a $1.5 \mathrm{~cm}$ layer of F20/F30 water-wet sand followed by a $2.1 \mathrm{~cm}$ layer of F20/F30 organic-wet sand. The remainder of the tank was packed with F20/F30 water-wet sand, with the exception of three lenses. Two F35/F50 lenses were emplaced $6.2 \mathrm{~cm}$ above the aluminum bottom, one layer was organic-wet and the other water-wet. The third lens was comprised of F70/F110 waterwet sand and was located $17.8 \mathrm{~cm}$ above the aluminum base. The entire packed region of the tank was $1.7 \mathrm{~cm}$ thick by $30.6 \mathrm{~cm}$ wide by $38.4 \mathrm{~cm}$ high and had an average porosity of $33 \%$. The effective intrinsic permeability of the packed region $\left(3.34 \times 10^{-10} \mathrm{~m}^{2}\right)$ was determined by maintaining constant head boundaries in the inlet and outlet wells and measuring the flowrate at steady state.

A known volume of PCE (47.33 ml) was injected with a syringe pump (Harvard Apparatus, South Natick, MA, 01760) during a 66.6-minute period at a constant rate $(0.71 \mathrm{ml} / \mathrm{min})$. The injection location was at the midpoint between the glass and the aluminum backing, $28.7 \mathrm{~cm}$ above the aluminum base.

During and subsequent to PCE injections, the migration of PCE was visually observed and recorded using a digital camera. It should be noted that experimental observations reflected only the PCE present in the first few millimeters of sand immediately adjacent to the glass. It is assumed here that observed behavior was representative of the entire tank thickness $(1.7 \mathrm{~cm})$. Direct measurement of the fluid saturations was not undertaken.

\section{Results:}

Figure 9 presents the time elapsed photos of the PCE infiltration experiment. Upon release, the PCE migrated down to the F70/F110 sand lens and pooled on top. Further downward migration did not occur until a pool of sufficient size developed and the PCE cascaded over the sides of the lens. The observations suggest that the PCE did not have the required entry pressure $\left(45.45 \mathrm{~cm} \mathrm{H}_{2} 0\right)$ to penetrate into the F70/F110 lens. 
$15 \mathrm{mins}$

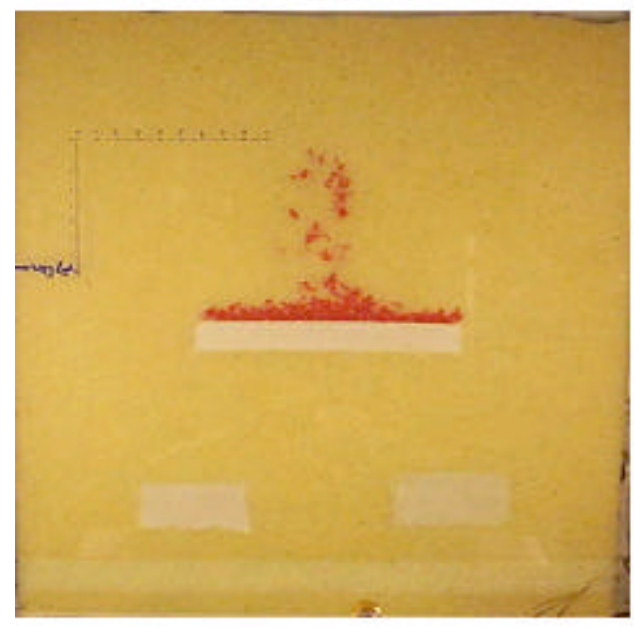

$45 \mathrm{mins}$

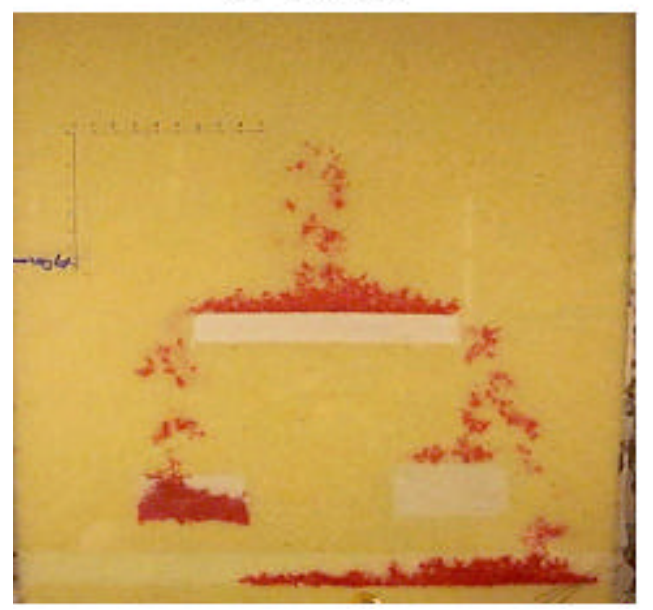

$30 \mathrm{mins}$

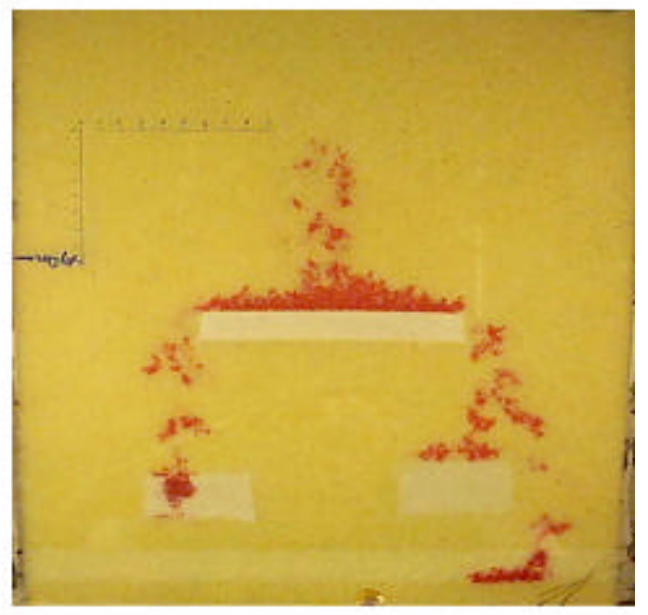

$67 \mathrm{mins}$

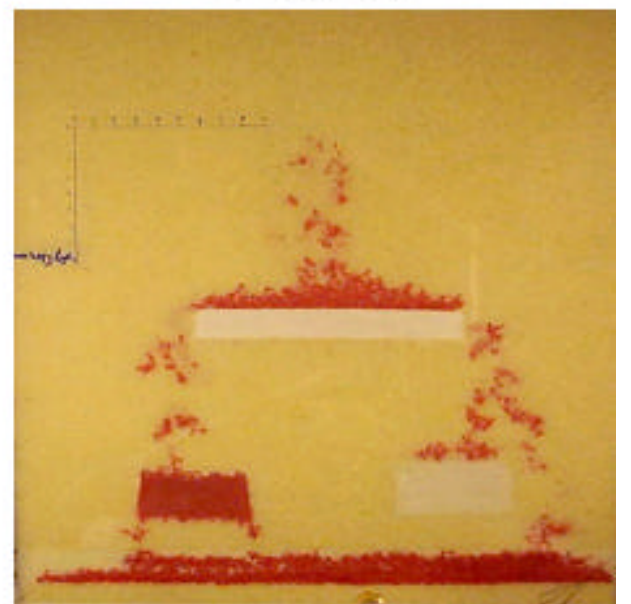

Figure 9 - Dyed PCE infiltration and redistribution in a physically and chemically heterogeneous water saturated system. Note that the PCE is retained in the PCE-wet f35-f50 and f20-f30 layers.

Similar pooling and cascading behavior occurred when the PCE reached the water-wet F35/F50 lens. Here again, the PCE did not have the required head $(16.94 \mathrm{~cm} \mathrm{H}$ water-wet F35/F50 lens. The spread of the PCE was greater than originally anticipated, as a result half of the PCE did not pool on top of the water-wet F35/F50 lens as expected. After cascading around the F70/F110 lens a portion of the PCE bypassed the water-wet F35/F50 lens and migrated directly down to the organic-wet F20/F30 layer, where it was retained.

In contrast, the PCE spontaneously imbibed into the organic-wet F35/F50 lens. The negative capillary entry pressure for the F35/F50 organic-wet lens facilitated PCE migration into this lens. Continued downward migration of PCE through this organic-wet lens occurred only after the lens neared complete PCE saturation as seen in Figure 10.

The F20-F30 organic-wet layer near the bottom of the tank retained PCE that migrated beyond the F35-F50 lenses. No PCE migrated into the water-wet F20/F30 layer below the organic-wet layer. Visual observations of PCE infiltration showed that the organic-wet sands act as a very effective capillary barrier, retaining PCE and inhibiting its downward migration. Upon completion of the PCE 
infiltration and redistribution event, high PCE saturations were present in the organic-wet F20-F30 and F35-F50 lenses, whereas low residual PCE saturations were present in the exposed F20-F30 waterwet soils. No PCE migrated into the wells at either side of the tank.

Hydraulic properties of the soils utilized in the two-dimensional infiltration studies discussed above have been measured. This information, in conjunction with the developed multiphase simulator, is currently being used to assess the ability of this simulator to predict observed DNAPL infiltration and redistribution behavior. The sand box observations are also being used to further refine constitutive hydraulic property models and to explore scale-up issues in modeling multiphase systems.

(iv) Development of innovative remediation schemes

Methods:

Subsequent experimental studies with this sand box setup were conducted to assess the ability of DNAPL-wet layers to contain mobilized DNAPL during surfactant flushing. A 4\% solution of sodium dihexyl sulfosuccinate (Aersol MA80i) and sodium dioctyl sulfosuccinate (Aersol OT100) was injected at $3 \mathrm{ml} / \mathrm{min}$ in the upper $19 \mathrm{~cm}$ of the sand box's right well.

\section{Results:}

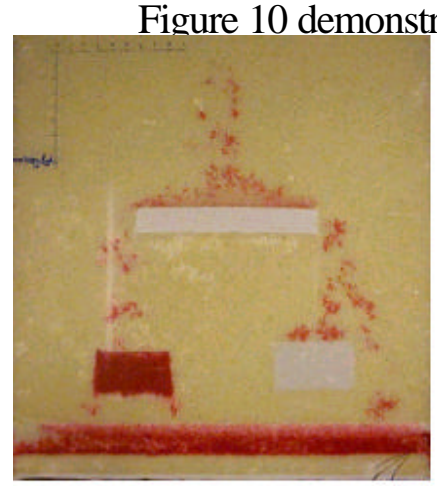

$30 \mathrm{mins}$

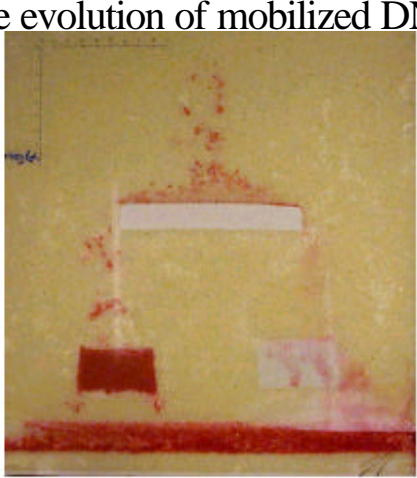

58 mins

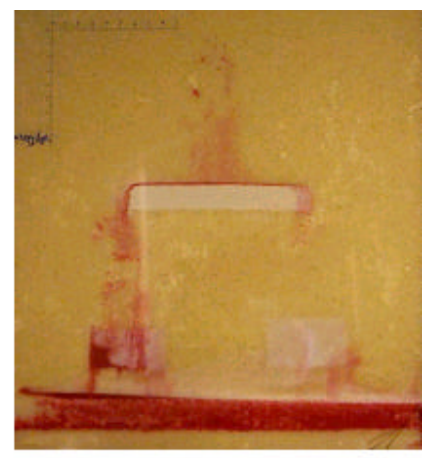

96 mins

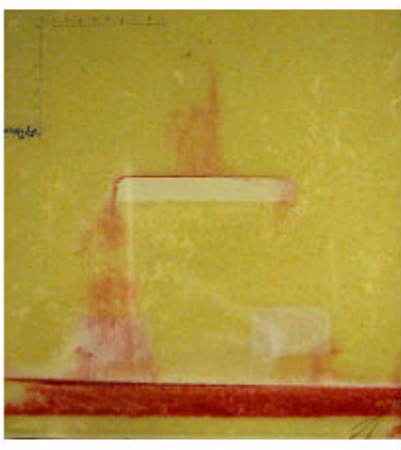

$121 \mathrm{mins}$

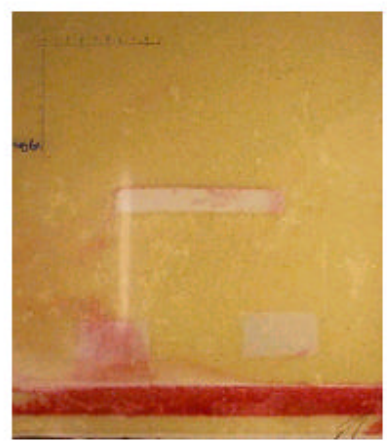

298 mins

Figure 10 - Time evolution of mobilized PCE during a surfactant flush. The surfactant solution $(g=0.1 \mathrm{dynes} / \mathrm{cm})$ is flowing from right to left above the bottom f20-f30 OTS layer. Note that the mobilized PCE is retained in the bottom organic-wet layer.

Observe that the bottom DNAPL-wet layer acts to retain and redirect mobilized DNAPL during surfactant flushing. Results from this study suggest that wettability alteration could be used in 
conjunction with other remediation schemes to improve their efficiency and performance. Soils could either be treated in situ or emplaced to create an organic wetting barrier. Mobile NAPLs would then be entrapped in a specific known location, the organic wetting barrier, and allow for targeted treatment.

The multiphase flow simulator that has been modified to incorporate soils of varying wettability could be used to model mobile NAPL, its entrapment in the organic wetting barrier and subsequent focused remediation schemes.

\section{RELEVANCE, IMPACT AND TECHNOLOGY TRANSFER}

Natural mineral surfaces display varying wettability characteristics. For example, shale and iron oxide coated media may be preferentially wetted by organics, whereas other aquifer materials, such as quartz and carbonate, are water-wet. In addition to natural wettability variations based upon mineralogy, temporal wettability alterations may also occur in the subsurface. Common surface-active components of NAPL waste mixtures may sorb to mineral surfaces and significantly change the wettability. A limited number of previous investigations have demonstrated that NAPL transport properties depend strongly on the wettability of porous media. This EMSP-sponsored research project has been designed to investigate the extent of wettability alteration in the presence of solvent waste mixtures and to quantify its influence on the transport and persistence of these organic liquids at contaminated sites.

Organic-wet sands and fractional wettability media used in the EMSP experiments described above have been produced through application of organic coatings in our laboratories. Although use of these model systems has facilitated careful quantification of wettability effects, field soils and wastes from DOE sites are typically more complex. In the new funding period, experiments will be undertaken using actual field soils and more complex NAPL mixtures. The analytic and predictive capabilities of the conceptual and parametric models developed in the previous funding period will be examined for these more representative soil/waste systems. In addition, the computer simulator will be extended and verified for these systems, so that it may be useful for site-specific assessments. Soils will be selected to represent a range in soil mineralogies encountered at field sites. Potential sites in the DOE complex include Idaho National Lab, Savannah River, Oak Ridge, Hanford, and Rocky Flats. Communication with DOE personnel at Hanford, Oak Ridge, and Savannah River has been initiated. Due to the presence of radioactive materials in many of the DOE field NAPL wastes, synthetic waste mixtures will be generated in our laboratories to simulate actual field mixtures.

As previously outlined, a two-dimensional multiphase flow simulator has been adapted to explore the influence of coupled physical and chemical heterogeneity on DNAPL migration and entrapment in the saturated zone. The two-dimensional simulations illustrate that the proposed constitutive capillary pressure/relative permeability/saturation relationships adequately characterize the experimental system and that the new constitutive relationships must be used to account for variable subsurface wettability. Although field conditions are significantly more complex than the twodimensional infiltration the proposed constitutive relationships used at the laboratory scale can be applied to the field scale.

To maximize the impact of our research efforts, the exchange of information and coordination of research is on going with other EMSP projects that relate to NAPL transport and remediation. Professor Susan Powers of Clarkson University (grant 70035) is exploring the influence of surfaceactive chemicals and/or microorganisms on the interfacial phenomena governing the migration of NAPLs in the unsaturated soil zone. Surface-active materials are present in complex NAPL mixtures and are produced through microbial metabolic processes. We are currently developing a work plan to enhance 
collaboration efforts. Activities will include, but not limited to, the use of common NAPLs and aqueous phase mixtures as well as the exchange of soil characterization data. Meetings between scientists in both groups have been held and additional meetings are planned throughout the summer. These interproject discussions and sharing of techniques have already benefited research projects of both groups.

In addition personnel at the Savannah River site have agreed to provide soil samples. Use of actual DOE site soils will be used in a variety of experiments with the ultimate goal to determine the fate of NAPLs and the remediation potential at DOE sites. Professor Powers is currently engaged in a sampling effort at Savannah River. We hope to collaboratively perform experiments on these samples in an effort to characterize the soil organic matter and, further, their surface chemistry characteristics.

\section{PROJECT PRODUCTIVITY}

A majority of the goals proposed for this project were accomplished with success. Significant inroads were made into developing a greater understanding of the effect of aqueous phase chemistry on interfacial properties and, by extension, flow and transport parameters. The work detailed in the publications by Lord et al. (1997ab, 1999, 2000) explored how organic acid and base chemistry can affect interfacial tension, solid phase wettability, and inter-phase partitioning. The phenomenological effects of hese mechanisms were demonstrated on air-water and organic-water capillary pressuresaturation curves. In addition, an apparatus was successfully developed and implemented to measure capillary pressure-saturation relationships in synthetically treated soils of varying wettability. Relative permeability models that take wettability properties into consideration were also developed [Bradford et al., 1997]. The multiphase flow simulator MVALOR was also modified to incorporate spatial wettability heterogeneity [Bradford et al., 1999] and its potential influence was explored through fieldscale simulations. Sand tank experiments and M-VALOR simulations demonstrated the remarkable effect of spatial chemical (wettability) heterogeneity on the distribution of oganic chemicals in the porous media [O'Carroll et al., in preparation].

One of the major goals of this research was to explore the effect of solid phase wettability on relative permeability. It was anticipated that the apparatus used to measure capillary pressure-saturation curves for these soils could also be used to estimate their relative permeability through an inverse modeling procedure. Unfortunately, the uniform nature of the soils examined coupled with the necessary modifications made to the experimental apparatus (to enable to use of fractionally-wet soils) yielded results that were relatively insensitive to relative permeability. Effort has been expended to redesign the apparatus to allow these properties to be more easily estimated. These efforts have carried over into the next phase of this research and as such this goal was not accomplished during the project period. Similarly, modifications to MISER (our compositional flow and transport simulator) that incorporate the compositional effects explored by Lord et al., are ongoing.

\section{PERSONNEL SUPPORTED}

Linda M. Abriola, Co-Principal Investigator

Avery H. Demond, Co-Principal Investigator

Scott A. Bradford, Research Scientist

Klaus Rathfelder, Research Scientist

Dave L. Lord, Ph.D. Student

Denis M. O'Carroll, Ph.D. Student

Thomas J. Phelan, Ph.D. Student 
Mark D. Wilkins, Ph.D. Student

Roger T. Echols, Masters Student

Jodi L. Ryder, Masters Student

Richard A. Vendlinski, Undergraduate Research Assistant

\section{PUBLICATIONS}

Bradford, S. A. and L. M. Abriola, 2001. Dissolution of residual tetrachloroethylene in fractional wettability porous media: Incorporation of interfacial area estimates. Water Res. Res. , 37(5), 1183-1195.

Bradford, S. A., L. M. Abriola, and F. J. Leij. 1999. Multi-fluid hydraulic properties for fractional wettability porous media. In: Characterization and Measurement of the Hydraulic Properties for Unsaturated Porous Media (Editors, M.Th. van Genuchten, F.J. Leij and L. Wu), University of California, Riverside, pp. 165-178.

Bradford, S. A., L. M. Abriola, and K. M. Rathfelder. 1998. Flow and entrapment of dense nonaqueous phase liquids in physically and chemically heterogeneous aquifer formations. $A d v$. Water Res., 22:117-132.

Bradford, S. A., L. M. Abriola, and F. J. Leij. 1997. Wettability effects on two- and three-fluid relative permeabilities. J. Contam. Hydrol., 28, 171-191.

Demond, A.H., K.F. Hayes, D.L. Lord, F. Desai and A. Salehzadeh. 1999. Impact of organic compound chemistry on capillary pressure relationships of sands. In: Characterization and Measurement of the Hydraulic Properties for Unsaturated Porous Media (Editors, M.Th. van Genuchten, F.J. Leij and L. Wu) University of California, Riverside, pp.229-240.

Lord, D.L., A.H. Demond, and K.F. Hayes. 2000. Effects of dodeclyamine chemistry on interfacial tension, wettability, and capillary pressure in multiphase subsurface waste systems, Transport in Porous Media, 38:79-92.

Lord, D.L. 1999. Influence of organic acid and base solution chemistry on interfacial and transport properties of mixed wastes in the subsurface. Ph.D. dissertation. Department of Civil and Environmental Engineering, The University of Michigan, Ann Arbor, MI.

Lord, D. L., K. F. Hayes, A. H. Demond, and A. Salehzadeh. 1997a. Influence of organic acid solution chemistry on subsurface transport properties. 1. Surface and interfacial tension. Environ. Sci. Technol., 31, 2045-2051.

Lord, D. L., A. H. Demond, A. Salehzadeh, and K. F. Hayes. 1997b. Influence of organic acid 
solution chemistry on subsurface transport properties. 2. Capillary pressure-saturation. Environ. Sci. Technol., 31, 2052-2058.

O'Carroll, D. M., S. A. Bradford, and L. M. Abriola. in preparation. Infiltration and redistribution of PCE in a system containing spatial wettability variations.

\section{INTERACTIONS}

Bradford, S. A., L. M. Abriola, A. H. Demond, and D. L. Lord. 1999. Migration and entrapment of DNAPLs in chemically heterogeneous aquifer environments. American Chemical Society, National Meeting, August 22-26, New Orleans, LA.

Bradford, S. A., and L. M. Abriola. 1998. Entrapment and dissolution of organic liquids in chemically heterogeneous porous media. In: IAHS Publication no. 250, Groundwater Quality: Remediation and Protection, Tuebingen, Germany, pp. 167-172.

Bradford, S. A., L. M. Abriola, and K. M. Rathfelder. 1998b. Simulated entrapment and dissolution of organic liquids in chemically heterogeneous porous media. In: Enviromeet 98-Behavior and Remediation of Nonaqueous Phase Contaminants in the Subsurface (Editors C.V. Chrysikopoulos, J. Bear, and T. C. Harmon), University of California, Irvine, pp. 7-16.

Bradford, S. A., L. M. Abriola, and T. J. Phelan. 1997. The impact of fractional wettability and grain size distribution on the long-term dissolution of residual tetrachloroethylene. Eos, Transactions, American Geophysical Union, vol.78, no.46, Suppl., 78:F331.

Bradford, S. A., L. M. Abriola, and K. M. Rathfelder. 1997. Flow and entrapment of nonaqueous phase liquids in physically and chemically heterogeneous aquifer formations. Eos, Transactions, American Geophysical Union, vol.78, no.17, Suppl.,. 78:S158-159.

Echols, R. T. and A. H. Demond. 1999. Impact of soil organic matter on the transport of organic liquids in soil. Midwest Environmental Chemistry Workshop, Houghton, MI.

Lord, D. L., A. H. Demond, K. F. Hayes, L. M. Abriola, S. A. Bradford and T. J. Phelan. 1998. Impacts of organic acid and base solution and interfacial chemistry on NAPL transport in the subsurface. Eos, Transactions, American Geophysical Union, vol.79, no.45, Suppl., 79:F247.

Lord, D. L., A. H. Demond and K. F. Hayes. 1998. Effects of solute chemistry on soil transport properties. $21^{\text {st }}$ Midwest Environmental Workshop, October 16-18, Ann Arbor, MI.

Lord, D. L., A. H. Demond, K. F. Hayes and A. Salehzadeh. 1998. Effects of surfactant chemistry on interfacial tension, wettability and capillary pressure in multiphase subsurface systems. In: Enviromeet 98- Behavior and Remediation of Nonaqueous Phase Contaminants in the Subsurface (Editors C.V. Chrysikopoulos, J. Bear, and T. C. Harmon), University of California, Irvine, pp. 20-23. 
Lord, D. L., A. H. Demond and K. F. Hayes. 1998. The impact of speciation, partitioning and sorption on the migration of multiple fluid phases in the subsurface. European Geophysical Society Hydrology and the Earth's Crust Symposium, XXIII General Assembly, April 20-24, Nice, France.

Lord, D. L., K. F. Hayes and A. H. Demond. 1997. The impacts of solution and interfacial chemistry on organic liquid migration in the subsurface. American Chemical Society, National Meeting, April 13-17, San Francisco, CA.

Lord, D. L., A. H. Demond and K. F. Hayes. 1997. The impact of solution chemistry on capillary pressure-saturation relationships for two-phase systems containing solutes. Eos, Transactions, American Geophysical Union, vol.79, no.45, Suppl., 97:H41E-08

O'Carroll, D. M., S. A. Bradford, and L. M. Abriola. 2000. Infiltration and redistribution of PCE in a system containing spatial wettability variations. 6th International Symposium on Evaluation of Reservoir Wettability and Its Effect on Oil Recovery, September 27-28, Socorro, NM.

Phelan, T. J., D. M. O'Carroll, S. A. Bradford, and L. M. Abriola. 2000. Evalutation of DNAPL transport parameters in fractionally wet porous media, Eos, Transactions, American Geophysical Union, vol.81, no.48, Suppl., H71B-07.

\section{TRANSITIONS}

Significant gains have been made in the phenomena governing mixed waste migration as a result of EMSP funding. Important multiphase flow indices and constitutive relationships have been related to $\mathrm{pH}$, concentration of surface-active species and mineralogy. In turn, these relationships will be used in multiphase flow simulators to better predict mixed waste migration at contaminated sites.

\section{PATENTS}

The project has not generated new inventions; in addition there are no patents pending.

\section{FUTURE WORK}

In the coming year, experimental research efforts will focus on the determination, quantification, and prediction of hydraulic property relations for various synthetic and natural porous media having a range of wettabilities. Results from these studies will be utilized in the development and design stages of the two-dimensional organic liquid infiltration experiments that will be initiated towards the end of the coming fiscal year. Concurrent efforts to quantify interfacial tension and wettability as a function of aqueous phase chemistry will be continued. Numerical modeling efforts will initially be directed towards the simulation of transient outflow experiments (to determine the relative permeability relations), and then two-dimensional infiltration experiments. Modifications to the simulator to account for concentrationdependent interfacial tension and wettability will be addressed as information and insight is gained from the above mentioned experiments. 


\section{LITERATURE CITED}

Abriola, L. M., K. Rathfelder, M. Maiza and S. Yadav, VALOR code version 1.0: A PC code for simulating immiscible contaminant transport in subsurface systems, EPRI TR-101018, Project 2879-08, Final Report, September, 1992.

Anderson, W. G., Wettability literature survey - Part 4: Effects of wettability on capillary pressure, $J$. Petroleum Technology, October, 1283-1300, 1987.

Bradford, S. A., and F. J. Leij, Wettability effects on scaling two- and three-fluid capillary pressure-saturation relations, Env. Sci. and Technol., 29, 1446-1455, 1995.

Cheng, P., Li, D, Boruvka, L., Rotenberg, Y., Neumann, A.W. 1990. Automation of axisymmetric drop shape analysis for measurement of interfacial tensions and contact angles. Colloids and Surfaces, 43, 151-167.

Dawson, H. E., and P. V. Roberts. Influence of viscous, gravitational, and capillary forces on DNAPL saturation. Ground Water 35:261-269, 1997.

Hofstee C, R.C. Walker and J.H. Dane, Infiltration and redistribution of perchloroethylene in stratified water-saturated porous media, Soil Sci. Soc. Am. J., 62, 13-22, 1998.

Hofstee C, R. C. Walker, J. H. Dane and R.C. Walker, Infiltration and redistribution of perchloroethylene in partially saturated, strafied porous media, J. Contam. Hydrol., 34, 293313, 1998.

Kueper B. H., D. Redman, R. C. Starr, S. Reitsma and M. Mah, A field experiment to study the behavior of tetrachloroethylene below the water table; spatial distribution of residual and pooled DNAPL. Groundwater, 31(5), 756-766, 1993.

MacDonald, J. A., Kavanaugh, M. C., Restoring Contaminated Groundwater: An Achievable Goal?, Environmental Science and Technology, 28:362A-368A, 1994.

National Research Council, Research Needs and Opportunities, Committee on Subsurface Contamination at DOE Complex Sites, National Research Council, Washington, D.C., 1998.

Oostrom, M., C. Hofstee, R. C. Walker and J. H. Dane, Movement and remediation of trichloroethylene in a saturated heterogeneous porous medium; 1, Spill behavior and initial dissolution. J. Contam. Hydrol., 37, 159-178, 1999.

Oostrom, M., C. Hofstee, R. C. Walker and J. H. Dane, Movement and remediation of trichloroethylene in a saturated heterogeneous porous medium; 2, Pump-and-treat and surfactant flushing. J. Contam. Hydrol., 37, 179-197, 1999.

Powers, S. E., and M.E. Tamblin, Wettability of porous media after exposure to synthetic gasolines. $J$. Contam. Hydrol., 19, 105-125, 1995. 
Powers, S. E., W. H. Anckner, and T. F. Seacord, Wettability of NAPL-contaminated sands. Journal of Environmental Engineering 122:889-896, 1996.

Pennell, K. D., M. Jin, L. M. Abriola and G. A. Pope, Surfactant enhanced remediation of soil columns contaminated by residual tetrachloroethylene. J. Contam. Hydrol., 16, 35-53, 1994.

Riley, R. G., J. M. Zachara, and F. J. Wobber, Chemical contaminants on DOE lands and selection of contaminant mixture for subsurface science research, U. S. Department of Energy, DOE/ER-0547T, 1992.

Salehzadeh, A. and A. H. Demond, Pressure cell for measuring capillary pressure-saturation relationships of contaminated sands. J. Env. Eng., 125(4), 385-388, 1999.

Sudicky, EA., A natural gradient experiment on solute transport in a sand aquifer: Spatial variability of hydraulic conductivity and its role in the dispersion process. Water Res. Res. 22, 2069-2082, 1986.

Thompson, A. F. B., R. Ababou and L. W. Gelhar, Implementation of the three-dimensional turning bands random field generator. Water Res. Res. 25, 2227-2243, 1989.

Woodbury, A. D. and E. A. Sudicky, The geostatistical characteristics of the Borden aquifer. Water Res. Res. 27, 553-546, 1991. 